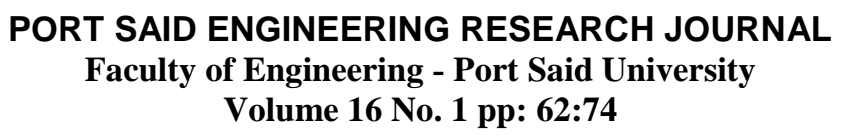

\title{
Mechanical and microstructural characterization of AA6061 reinforced with SiC particles
}

\author{
H.G. Salema , W.H. El_Garaihy ${ }^{b}$, and El-sayed M. A. Rassoulc, \\ aMechanical Engineering Department, School of Science and Engineering, American University in Cairo. \\ ${ }^{b}$ Mechanical Engineering Department, Faculty of Engineering, Suez Canal University. \\ ${ }^{c}$ Production Engineering and Mechanical Design Department, Faculty of Engineering, El_Mansoura University.
}

\section{Abstract}

AA 6061 reinforced with four different volume fractions of $\operatorname{SiCp}(5,10,15$, and $20 \%$ ) were produced by powder metallurgy processing using hot compaction (HC) temperature ranging from $400-500^{\circ} \mathrm{C}$. The effect of $\mathrm{HC}$ temperature and the volume fraction of the $\mathrm{SiC}$ reinforcement were investigated for the degree of consolidation, hardness profile, and microstructural evolutions. Microhardness measurement were taken to assess the variation in hardness across the diameters of the disks and following a rectilinear grid pattern to give color-coded maps of the hardness distributions. The highest Vickers hardness results were produced for AA6061 reinforced with 15\% SiC. Increasing SiC volume fraction impeded grain boundaries diffusion, which resulted in lower grain coarsening of the AA6061 matrices. Comparing the relative densities and Vickers hardness of the hot compacted samples, the $\mathrm{HC}$ temperatures ranging from $400-500{ }^{\circ} \mathrm{C}$ had insignificant influence on the densification and hardness results.

\section{Introduction}

Aluminium alloys have a wide variety of industrial applications because of their low density and good workability. Although, aluminium alloys offer important advantages in terms of their specific strength, corrosion resistance and thermal conductivity, their use is limited by their relatively low yield strength, and poor tribological characteristics [1-3]. Aluminium alloys are one of the most important groups of structural materials in various industries, the low hardness and low wear resistance, however, have limited the applicability of aluminium alloys in certain cases [4]. The aim to increase aluminium strength for applications in the aerospace and aeronautics industries has motivated the study of aluminium matrix composites. Recently, a number of composites have presented excellent mechanical properties at both, medium $(473 \mathrm{~K})$ and room temperatures [5-8]. It is well known now that aluminium, aluminium alloys, and aluminium composites can be strengthened by dispersing hard particles such as carbides, oxides or nitrides into the aluminium matrix by using different techniques in the solid or liquid state [9]. In particular aluminium composites can be prepared in the solid state by powder metallurgy (PM), which additionally presents versatility and lower production costs. This type of composite production process involves the mixing of reinforcement particles with the metallic powder, followed by consolidation and sintering processes. Other methods also include mechanical alloying (MA) and mechanical milling $(\mathrm{MM})$, which renders composites with fine and homogeneous distributions of the particles [10-11].

A number of researches investigations have been carried out in recent years to develop engineering materials that are stronger, stiffer, and more wear-resistant than the presently available commercial materials [12-15]. Metal matrix composites (MMCs) are regarded as excellent materials to obtain properties that are superior to those of the constituent phases and also to satisfy the above requirements. However, the higher cost of processing the composites limits their use. MMCs have become increasingly used for critical structural applications in industrial sectors because of their excellent stiffness to density and strength to density ratios. Aluminum is the most popular matrix for the metal matrix composites. MMCs can be reinforced with continuous fibre or discontinuous particles or whiskers [16]. Particlereinforced MMCs possess distinct advantages over fibre reinforced composites in terms of low cost and isotropic mechanical properties considerations. In general, ceramic particulates are prepared independently prior to composite fabrication. The particulates are introduced into the matrices via ingot casting and powder metallurgy (PM) processes. In the latter route, the scale of the reinforcing phase is limited by the starting powder size, which is typically of the order of microns to tens of microns and rarely below $1 \mu \mathrm{m}$. It is generally known that agglomeration of ceramic particulates could occur during PM processing of the MMCs. Agglomeration of reinforcement could lead to the composites having poorer mechanical strength and toughness. Uniform distribution of ceramic particulates in the matrices of MMCs is essential to achieve effective load-bearing capacity of the reinforcement. Moreover, possible interfacial chemical reactions between the reinforcements and the matrix could also degrade the mechanical properties of ex-situ MMCs [17-19]. 


\section{Materials and Experimental Procedure}

\subsection{Materials}

The investigated aluminium alloy 6061 (AA6061) was received in the form of powder with 30 Micron average size, as shown in Fig. 1a at low magnification.

AA6061 particles were characterized by uniformity in shape with variation in size from 10 to $45 \mu \mathrm{m}$ as shown in Fig1b at high magnification. SiC intermetallic powder with average particles size of $100 \mu \mathrm{m}$ was milled using high energy Planetary ball mill at a rotation speed of 500 rpm, ball -to- powder ratio of $(30: 1)$ for 72 hours duration at room temperature in agate jars and agate balls $(10 \mathrm{~mm}$ in diameter). After milling, the $\mathrm{SiC}$ powder particles size was reduced to $\approx 1 \mu \mathrm{m}$, while clustered particulate were found to be 25 Micron. Fig.2a, 2b shows SEM images for the $\mathrm{SiC}$ powder before and after milling. Figure 3 shows the particles size distribution of AA6061, Fig.4 shows the clusters size distribution of SiC powder after milling. The milled powder was used for AA6061 reinforcement. Four different volume fractions of $\operatorname{SiC}(5,10,15$, and 20\%) were chosen for the reinforcement of AA6061 matrices.

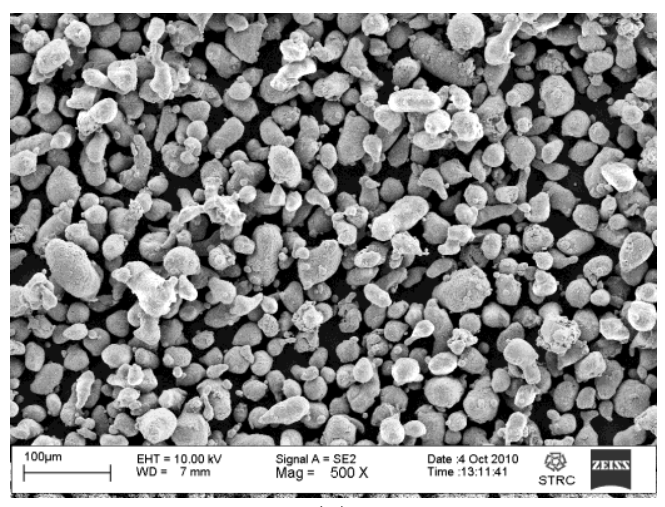

(a)

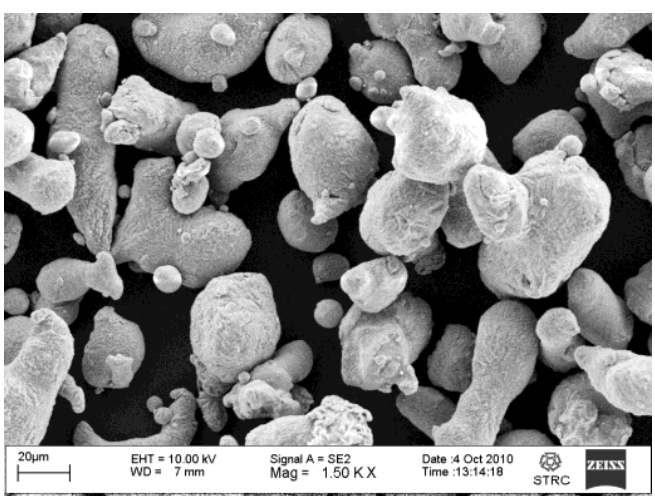

(b)

Fig.1 SEM images for AA6061 powder at: (a) low magnification; (b) high magnification.

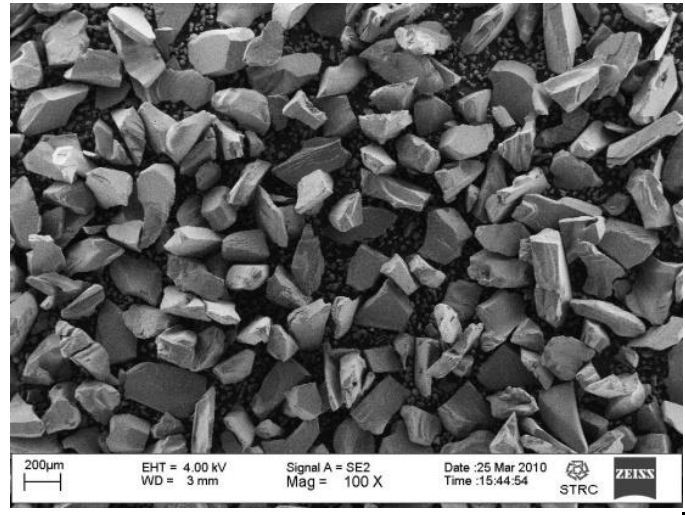

(a)

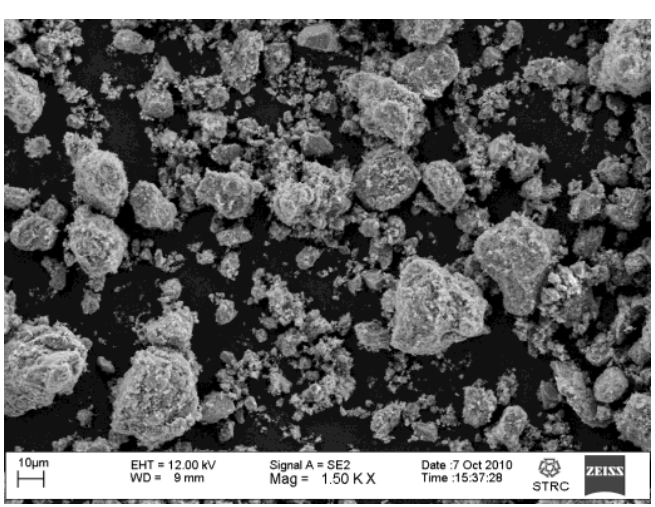

(b)

Fig.2 SEM images for SiC powder: (a) as received powder; (b) milled powder. 


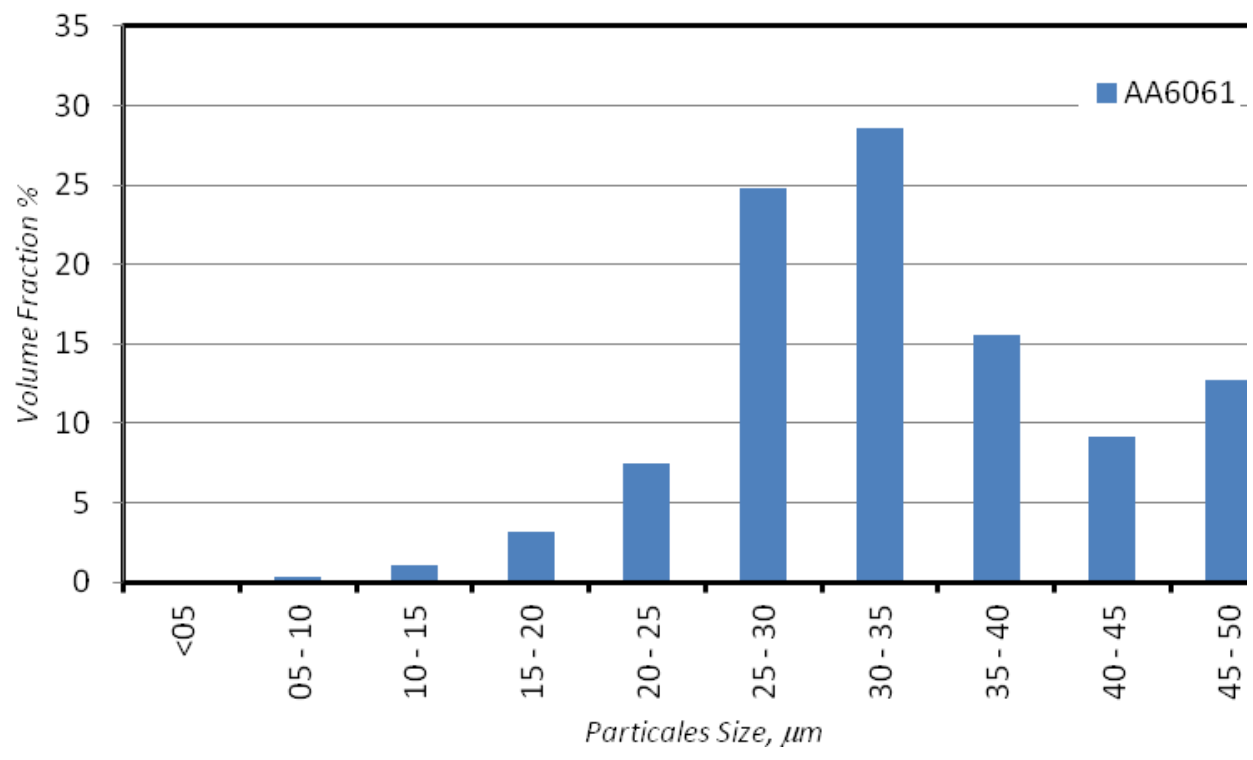

Fig.3 Particles size distribution of AA6061.

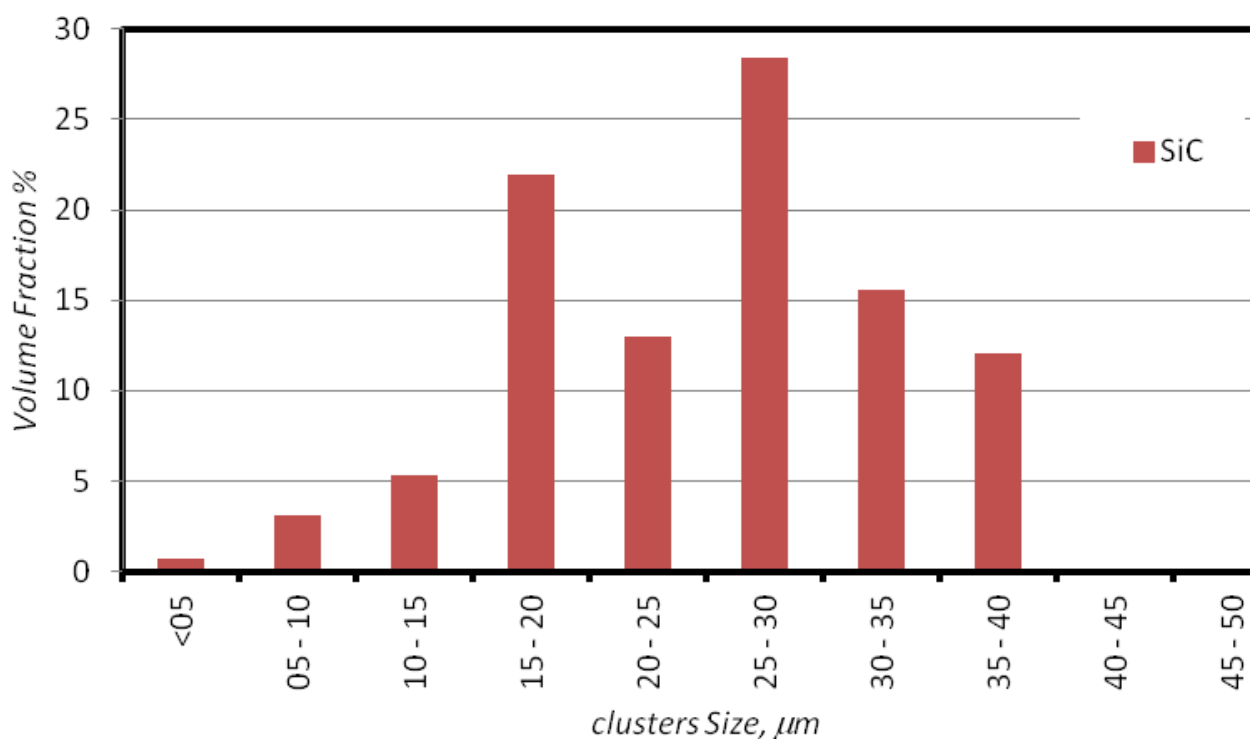

Fig.4 SiC clusters size distribution.

\subsection{Mixing}

To fabricate the AA6061-SiC composite, the required fractions of AA6061 and SiC powders were mixed under vacuum in Argon atmosphere in a glove box followed by mixing in a turbula blender operating at a rotation speed of $96 \mathrm{rpm}$ for $3 \mathrm{hrs}$.

\subsection{Compaction and sintering}

The obtained mixtures were uniaxially hot compacted into cylindrical sample $10 \mathrm{~mm}$ in diameter and $10 \mathrm{~mm}$ in height. The compaction process was carried out at compaction pressure of $525 \mathrm{MPa}$ at temperatures of 400 , 450 , and $500{ }^{\circ} \mathrm{C}$ for $30 \mathrm{~min}$. Variable temperatures were investigated so that the lowest compaction temperature suitable for producing an intact solid samples is obtained to minimize grain coarsening associated with sintering as a primary processing stage. Table 1 lists the hot compaction conditions for the various composite mixtures investigated in the current research.

Table 1 AA6061/SiC composite condition at constant pressure of $525 \mathrm{MPa}$ for $30 \mathrm{~min}$ as a function of temperature and $\mathrm{SiC}$ volume fractions. 


\begin{tabular}{|c|c|c|}
\hline Condition No. & Temperature $\left({ }^{\mathbf{0}} \mathbf{C}\right)$ & SiC\% \\
\hline 1 & 400 & 0 \\
\hline 2 & 450 & 0 \\
\hline 3 & 500 & 0 \\
\hline 4 & 400 & 5 \\
\hline 5 & 450 & 5 \\
\hline 6 & 500 & 5 \\
\hline 7 & 400 & 10 \\
\hline 8 & 450 & 10 \\
\hline 9 & 500 & 10 \\
\hline 10 & 400 & 15 \\
\hline 11 & 450 & 15 \\
\hline 12 & 500 & 15 \\
\hline 13 & 400 & 20 \\
\hline 14 & 450 & 20 \\
\hline 15 & 500 & 20 \\
\hline
\end{tabular}

\subsection{Characterization}

Density of the specimens was measured using Archimedean principle using Mettler Toledo densitometer by determining the specimens mass and volume, based on the apparent loss of weight after immersing the specimen in Xylene. Relative density of the composite was determined as a function of the theoretical density. Sample preparation was conducted through consecutive steps of grinding using Buehler $\mathrm{SiC}$ grinding paper with grits of $240,320,400,600,800$, and 1200 , then polished using 1.0 micron $\mathrm{Al}_{2} \mathrm{O}_{3}$ powder (Buehler ltd) as a polishing media. Keller's reagent and a $0.5 \% \mathrm{HF}$ solution were used as etchant [.

Macrohardness measurements were conducted on the polished surfaces without etching using digital metallic Vicker's hardness tester (TH 721). Testing was carried out on the surfaces under applied load of $10 \mathrm{~N}$ for $15 \mathrm{sec}$ dwell time. Vickers macro hardness HV measurements were recorded on the polished surfaces so that a rectilinear grid pattern defined by the two arbitrary axis $\mathrm{X}$ and $\mathrm{Y}$ was produced to show the hardness profile across the surface of the samples. These two axes were established so that they lie parallel to two perpendicular diameters on the surface of each disk with the position $(0,0)$ representing the centre of each sample as shown in Fig 5. The macrohardness measurements were taken using two different procedures. First, individual values of HV were recorded across the diameter of each disk in incremental steps of $0.5 \mathrm{~mm}$. At each selected point, the average hardness was obtained by taking individual measurements of $\mathrm{HV}$ at four separate points uniformly positioned around the selected point at equal distances from the point of $0.15 \mathrm{~mm}$. These measurements provided detailed quantitative information on the precise variation of $\mathrm{HV}$ across the diameter of each disk under different testing conditions, and by taking four separate values at each point it was possible to estimate the associated error bars at the $95 \%$ confidence level. Second, individual measurements of $\mathrm{HV}$ were recorded on the surface of each disk following a regular grid pattern with a spacing of $0.5 \mathrm{~mm}$ between each separate point. Following the procedure introduced in earlier experiments, these individual values of HV were then plotted as color-coded contour maps depicting the variation of the local hardness across the surface of each sample.

Microstructural characterization of the prepared surfaces of the samples was carried out using a Lica optical microscopy (OM) on the etched surfaces.

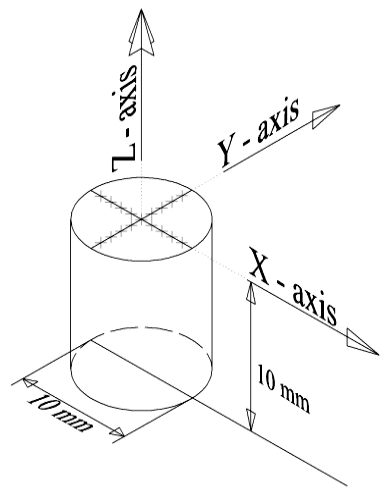

Fig. 5 Schematic drawing showing the hardness measuring points relative to $X$ and $Y$ axis. 


\section{Results}

\subsection{Density}

Figure 6 shows the relative density variation as a function of hot compaction temperatures for of $\mathrm{SiC}$ content $(0 \%, 5 \%, 10 \%, 15 \%$, and $20 \%)$. It showed that the relative density slightly decreased with increasing the hot compaction temperature. From Fig. 6 it is obvious that the lower the SiC content, the higher of the densification for all compaction temperatures. However, it is clear that hot compaction temperature of $400-500^{\circ} \mathrm{C}$ had insignificant influence on the densification. Accordingly, $400^{\circ} \mathrm{C}$ compaction temperature was selected as the lowest temperature that is most suitable for producing intact compact disks.

\subsection{Macrohardness measurements}

It is convenient to take the hardness measurements and plot them in a three dimensional form where by the individual values of $\mathrm{HV}$ are plotted against the position of each point defined in terms of $\mathrm{X}$ and $\mathrm{Y}$ axes. These 3-D displays provide simple pictorial display of the hardness distribution throughout the surface of each sample; also, color- coded contour maps showing the Vickers macro hardness across the surface of samples were done. Hardness profiles of the unreinforced AA6061 and their composites containing different volume fraction of $\mathrm{SiC}(5$, 10, 15, and 20\%) using different hot compaction temperature are shown in Figs 7-11. It is apparent from
Fig. 7 that the macrohardness distribution of the unreinforced sample is homogeneous, with average macrohardness value of ( $\mathrm{HV} \sim 63$ as Fig. 7a, HV 61 as Fig. $7 b$, and $\mathrm{HV} \sim 60$ as Fig. 7c). The hardness increased when using reinforcement of $5 \% \mathrm{SiC}$ and the distribution still uniform as seen in Fig. 8, with average hardness value of (HV $\sim 78$ as Fig. 8a, HV $\sim 76$ as Fig. 8b, and HV 72 as in Fig. 8c). The variation of hardness using reinforcement of $10 \% \mathrm{SiC}$ shown in Fig. 9, with average hardness value of (HV $\sim 88$ as Fig. 9a, HV $\sim 82$ as Fig. 9b, and HV $\sim 77$ as in Fig. 9c). Fig. 10 shows the hardness distribution in case of using $15 \% \mathrm{SiC}$ content, the average hardness became (HV $\sim 96$ as Fig. 10a, HV $\sim 10$ as Fig. 10b, and HV 78 as in Fig. 10c). With using reinforcement of $20 \% \mathrm{SiC}$ the average hardness was ( $\mathrm{HV} \sim 89$ as Fig. 11a, HV $\sim 87$ as Fig. 11b, and HV 87 as in Fig. 11c). The value of the Vicker's macrohardness that, recorded across the diameter of each sample against the distance from the centre were plotted in Fig. 12, these data delineate the results obtained when conducting hot compaction of samples of the unreinforced AA6061 and their composites containing different volume fraction of $\operatorname{SiC}(5,10,15$, and $20 \%)$ using different hot compaction temperature. From the results shown in Figs. 7-12, it is clear that the hardness increase in the centre of the disc and decrease as the point of measuring be close to the edge. We can conclude from these figures that the hardness increase by increasing the $\mathrm{SiC}$ content, and that for the samples with the same $\mathrm{SiC}$ volume fraction, the hardness is slightly decreased by the increase of hot compaction temperature.

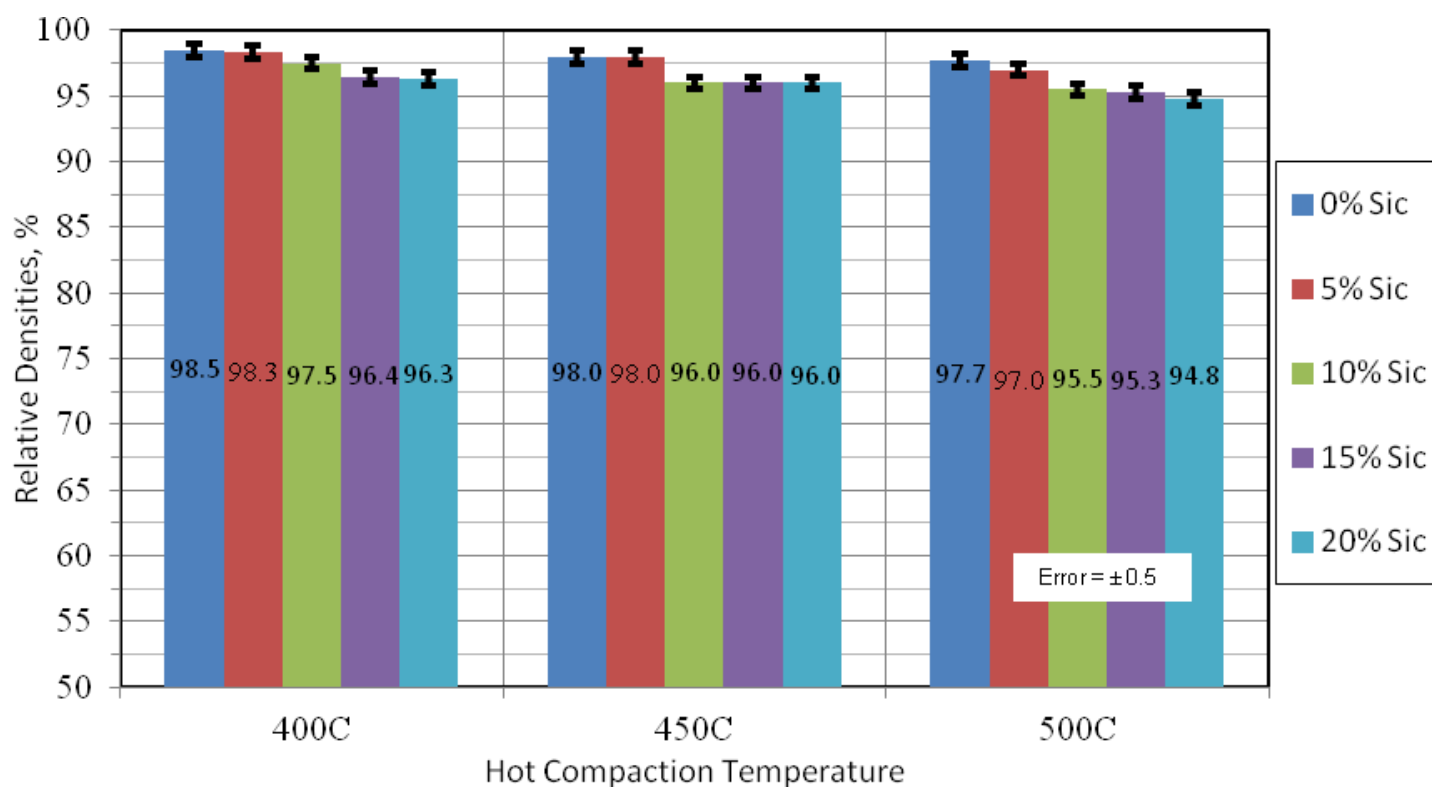

Fig.6 The relative density of AA6061 samples with different volume fraction of $\mathrm{SiC}$ reinforcements. 


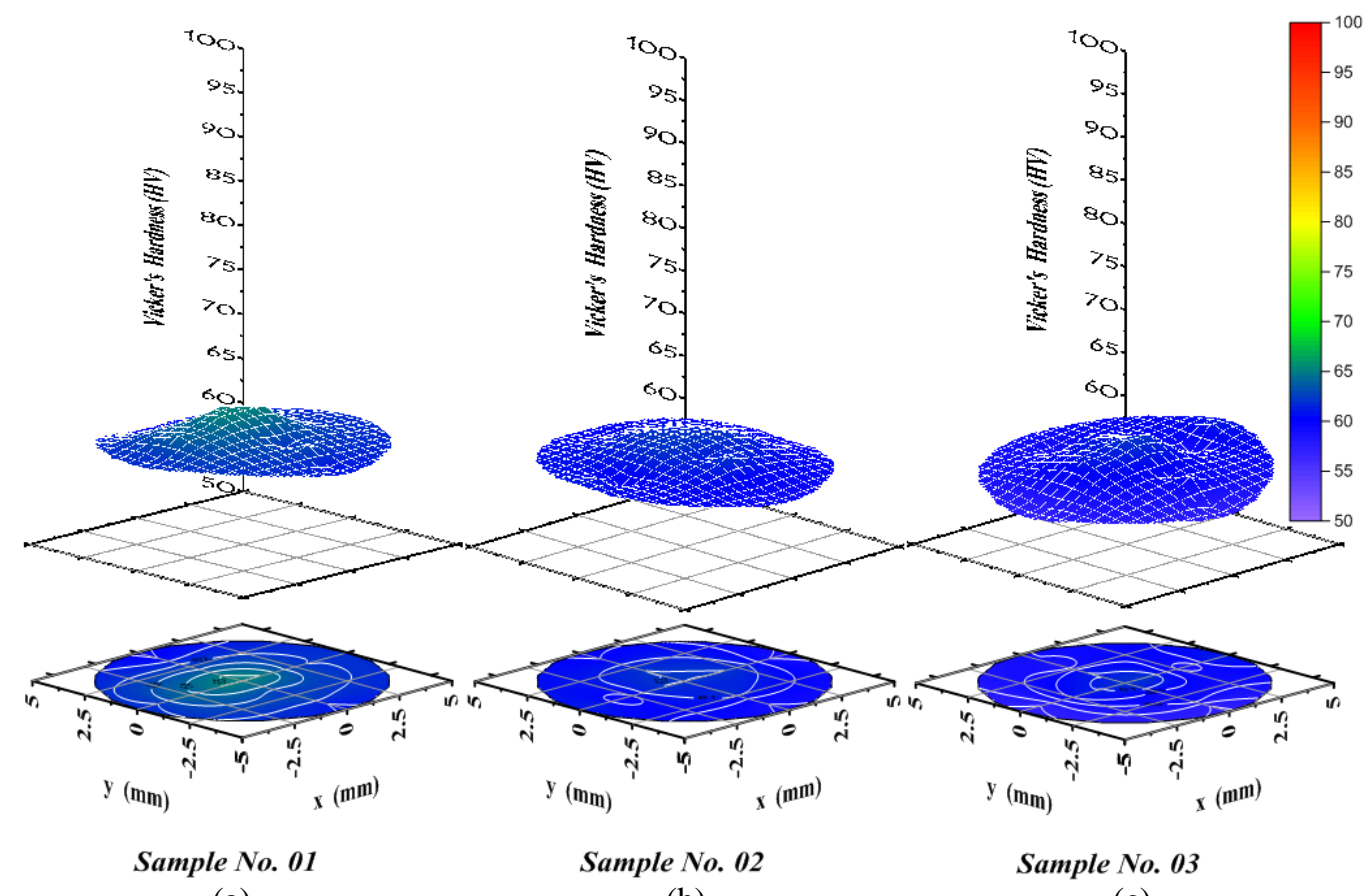

(a)

(b)

(c)

Fig. 7 Three dimensional representation and color-coded contour maps showing hardness distribution across the surface for $0 \% \mathrm{SiC}$ samples.

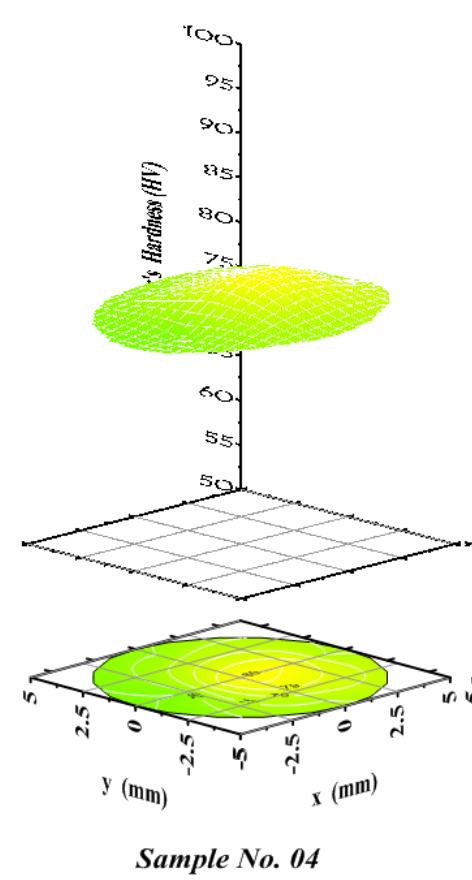

(a)

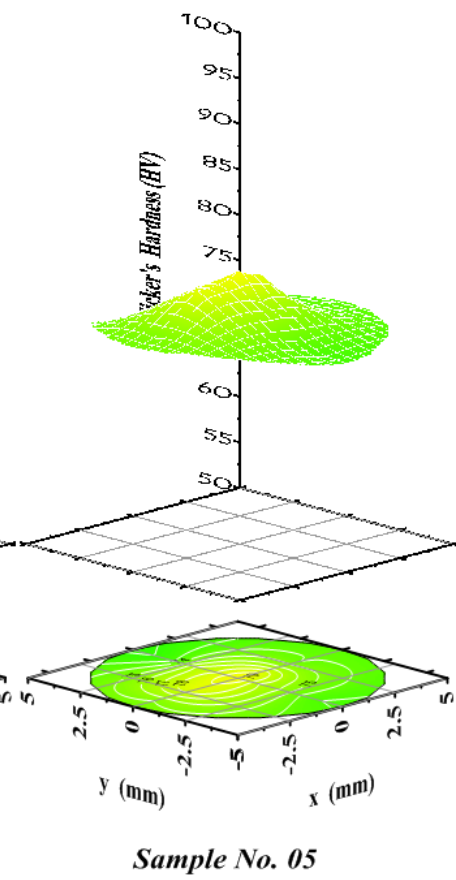

(b)

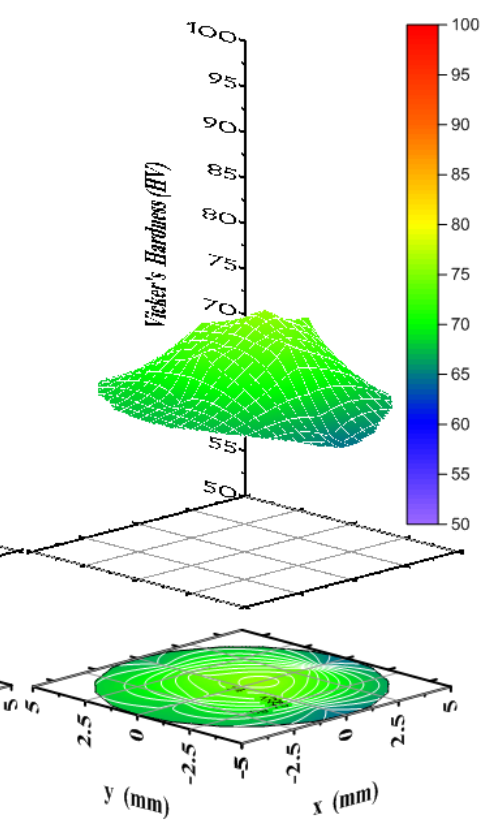

Sample No. 06

(c)

Fig. 8 Three dimensional representation and color-coded contour maps showing hardness distribution across the surface for $5 \% \mathrm{SiC}$ samples. 


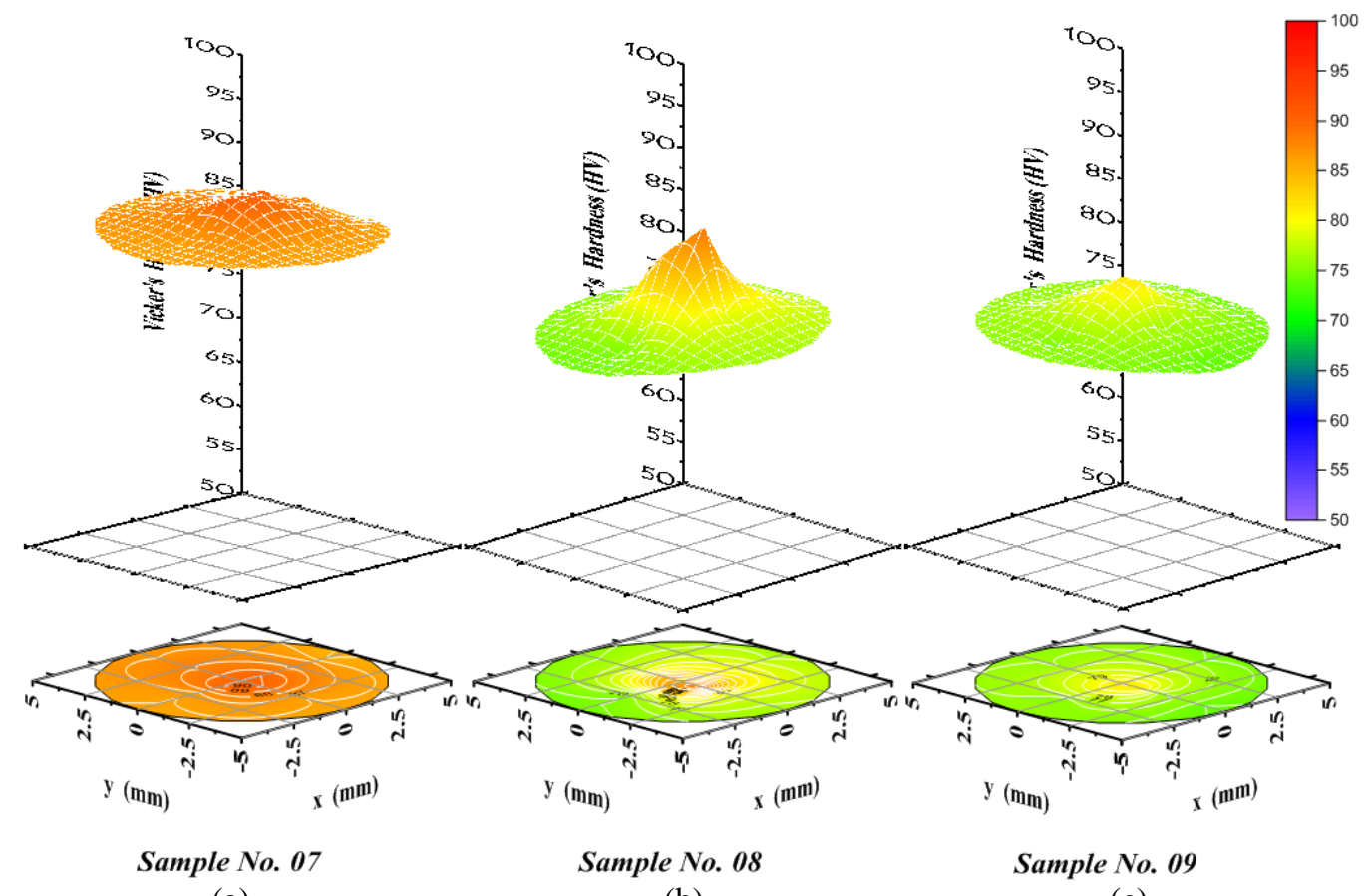

(a)

(b)

(c)

Fig. 9 Three dimensional representation and color-coded contour maps showing hardness distribution across the surface for $10 \% \mathrm{SiC}$ samples.

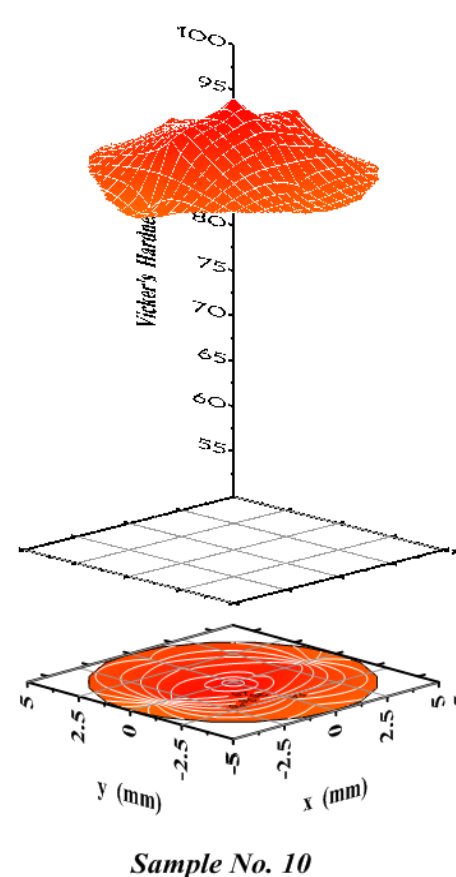

(a)

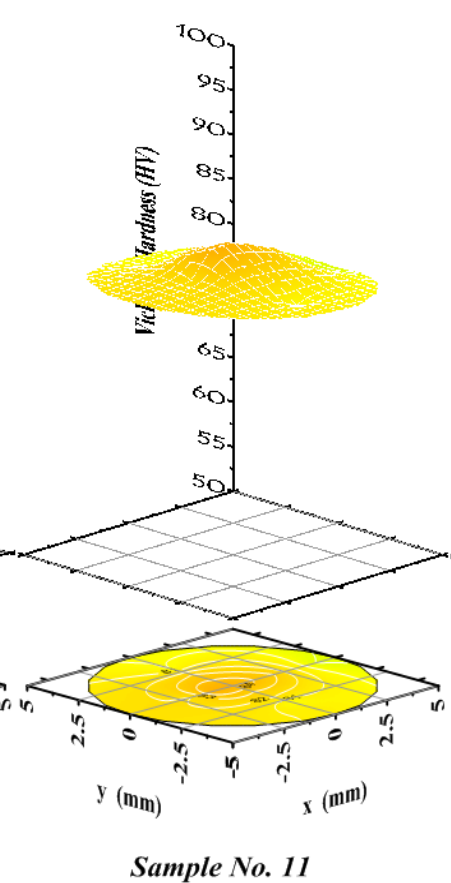

(b)

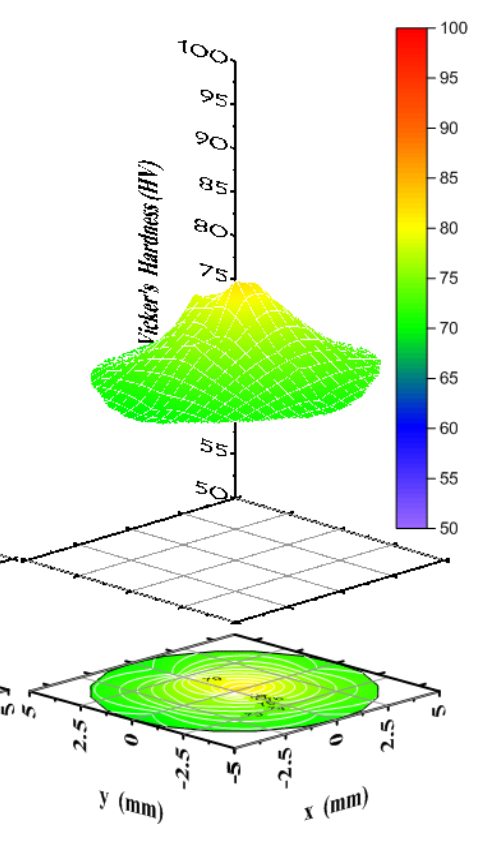

Sample No. 12

(c)

Fig. 10 Three dimensional representation and color-coded contour maps showing hardness distribution across the surface for $15 \%$ SiC samples. 


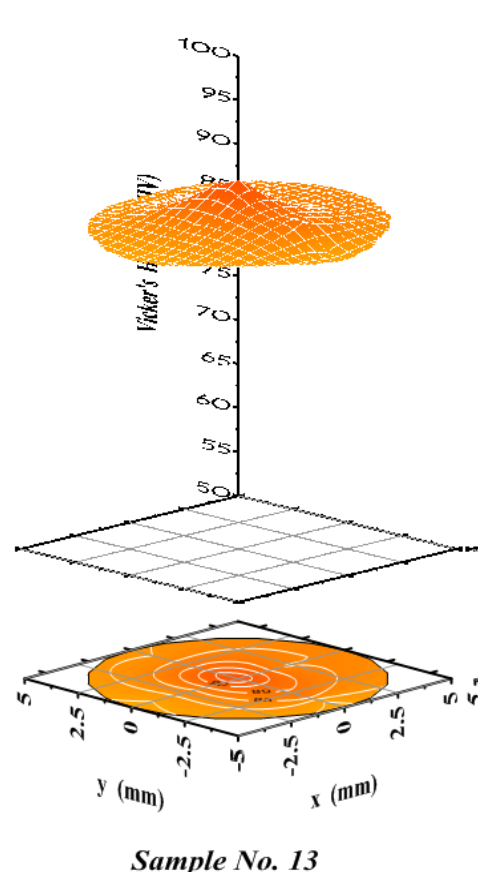

(a)

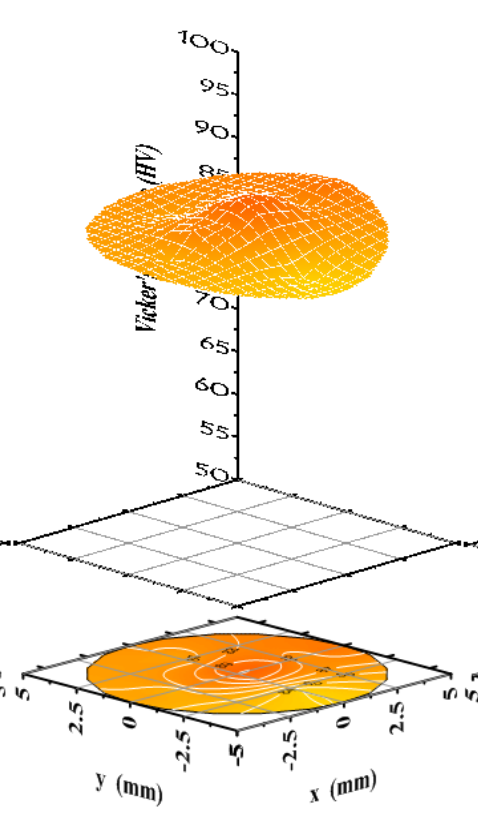

Sample No. 14

(b)

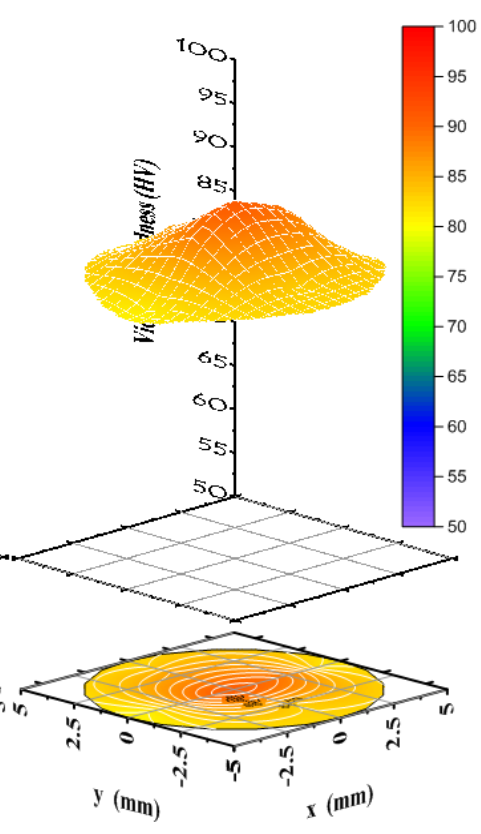

Sample No. 15

(c)

Fig. 11 Three dimensional representation and color-coded contour maps showing hardness distribution across the surface for $20 \% \mathrm{SiC}$ samples.

\subsection{Microstructural evolutions}

Optical micrographs of both pure AA6061 aluminium alloy and its reinforced composites containing different volume fractions of $\mathrm{SiC}$ in the as hot compact condition are shown in Fig. 13 at high magnification. It is observed that $\mathrm{SiC}$ particles were distributed with the AA6061 matrices along their boundaries and at triple junctions. Some of the segregated $\mathrm{SiC}$ particles were associated with voids as shown in Figs. 13(d-o) for all reinforced matrices conditions. In addition, the volumetric voids increased by increasing the $\mathrm{SiC}$ content. It was clear that, the coarsening of the grain size increased by increasing the hot compaction temperature. Table 2 shows the average grain size for the different samples. It was shown that increasing $\mathrm{HC}$ temperature increases the grain size; however, for the same $\mathrm{HC}$ temperature increasing the $\mathrm{SiC}$ content resulted in a decrease in grain size.

\section{Discussion}

As shown from Fig. 6, increasing of $\mathrm{SiC}$ content leads to a decrease in relative density [21]. This can be attributed to the introduction of the brittle of $\mathrm{SiC}$ into the ductile matrix of AA6061 which leads to increasing the segregation between the reinforcement and matrix by increasing the $\mathrm{SiC}$ reinforcement content. This could be verified by the microstructure, where increasing the amount of cavitations is proportional to the increase in amount of reinforcement. The possible mechanism may be explained by means of porosity evolution such that the fine pores at the particles interfaces have prevented the progress of densification which agreed with [22]. Comparing the results produced at different temperatures, the applied temperatures had insignificance influence on the densification took place. As the melting temperature of $\mathrm{SiC}$ is $2830 \mathrm{C}^{\circ}$, it is anticipated that there will be no coarsening accompanied during compaction where as for the matrix of alloy AA6061 coarsening was obvious by increasing of hot compaction temperature.

It is important to note that the hardness profile plots provide information on the degree of hardness homogeneities across the compact disks cross section. Numerous earlier reports demonstrated a direct correlation between the measured values of the Vickers macro hardness and the internal microstructures either observed directly by transmission electron microscopy and optical microscope or interpreted through the use of X-ray diffraction measurements [23]. Accordingly, it is reasonable to anticipate that measurements of hardness represent a simple and expedient procedure for the influence of $\mathrm{HC}$ on the homogeneity of structure produced of each content. 


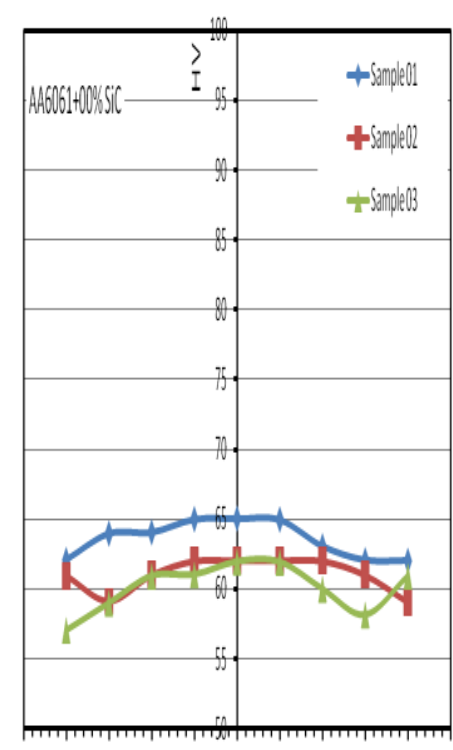

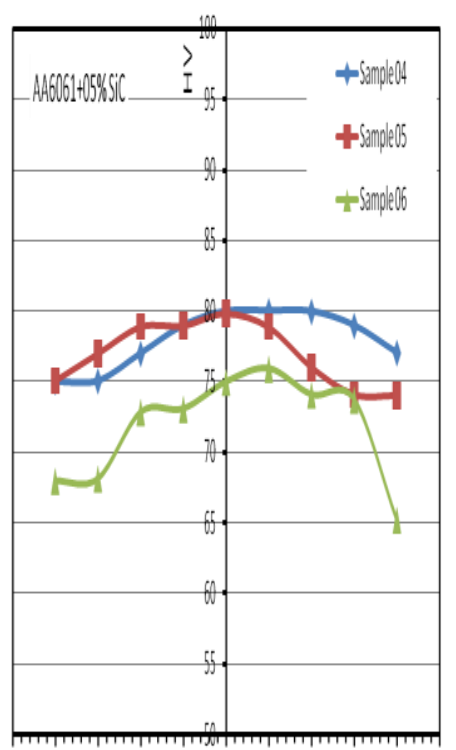

Distoncefon centre, $\mathrm{mm}$

(b)

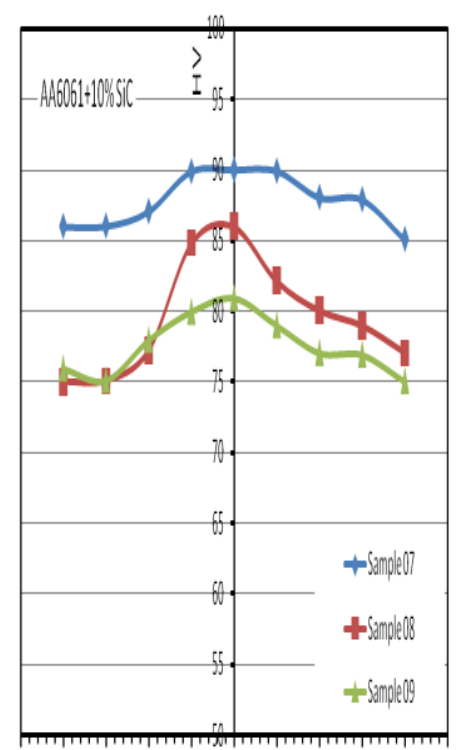

Distanceftrom centre, mm

(c)
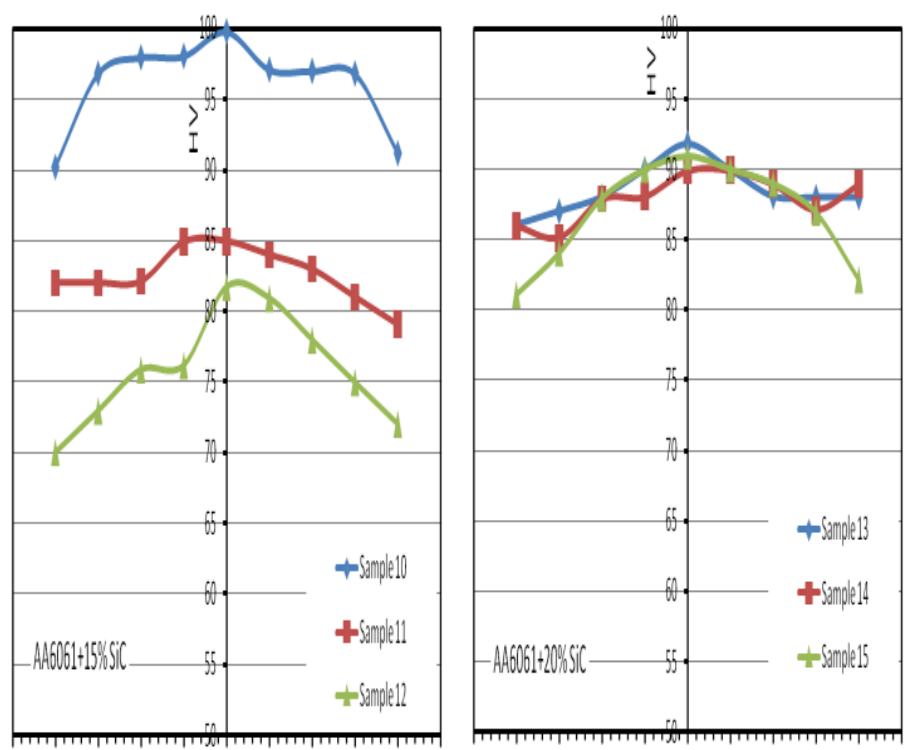

Disancetrom centre, mm

(d)

\section{Distancefrom centre, nm}

(e)

Fig. 12 Variation of $\mathrm{VHN}$, with distance from the centre of the HC specimen as a function of volume fraction of SiC:

(a) $0 \% \mathrm{SiC}$ (b) $5 \% \mathrm{SiC}$ (c) $10 \% \mathrm{SiC}$ (d) $15 \% \mathrm{SiC}$ (e) $20 \% \mathrm{SiC}$ 


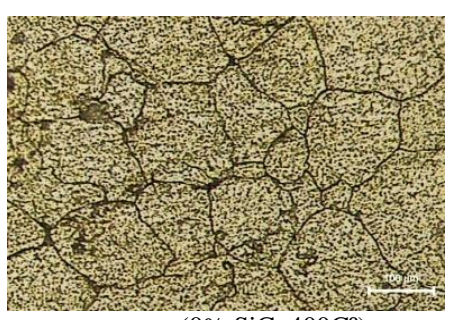

a- $\left(0 \% \mathrm{SiC}, 400 \mathrm{C}^{\circ}\right)$

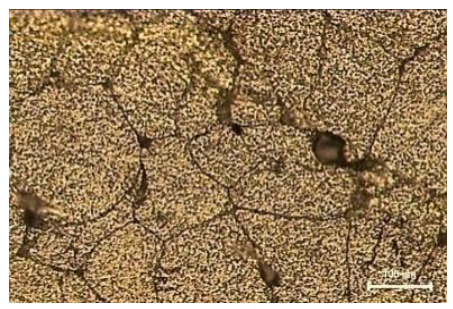

d- $\left(5 \% \mathrm{SiC}, 400 \mathrm{C}^{\circ}\right)$

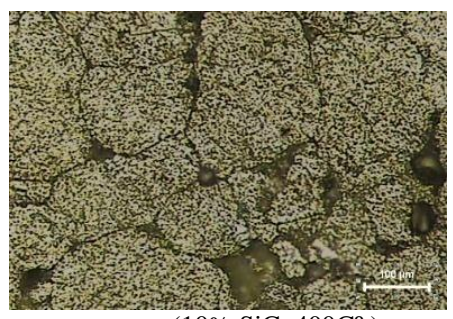

g- $\left(10 \% \mathrm{SiC}, 400 \mathrm{C}^{\circ}\right)$

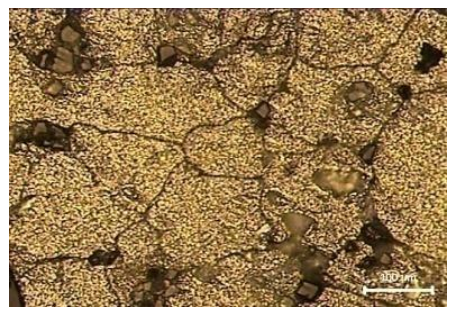

j- $\left(15 \% \mathrm{SiC}, 400 \mathrm{C}^{\mathbf{o}}\right)$

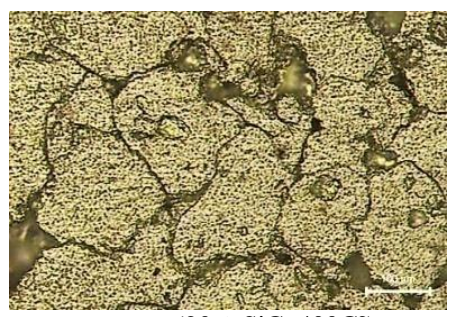

$\mathbf{m}-\left(20 \% \mathrm{SiC}, 400 \mathrm{C}^{\circ}\right)$

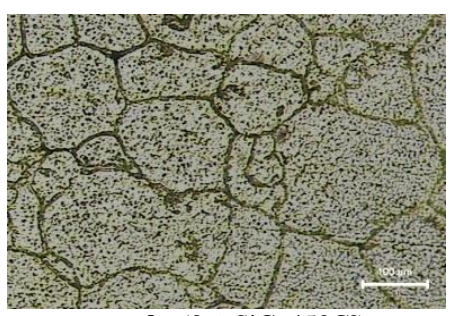

b- $\left(0 \% \mathrm{SiC}, 450 \mathrm{C}^{\circ}\right)$

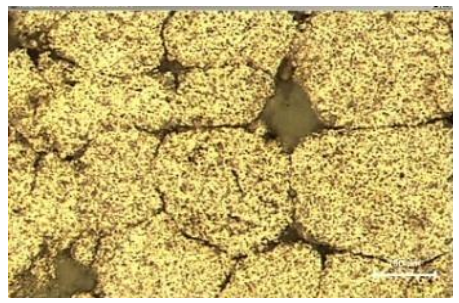

e- $\left(5 \% \mathrm{SiC}, 450 \mathrm{C}^{\circ}\right)$

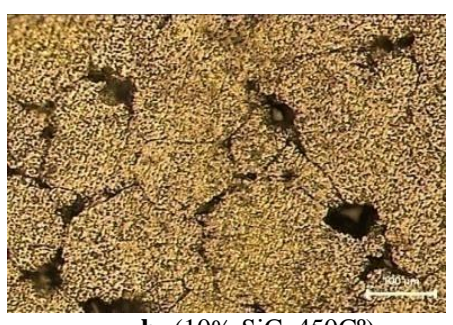

h- $\left(10 \% \mathrm{SiC}, 450 \mathrm{C}^{\circ}\right)$

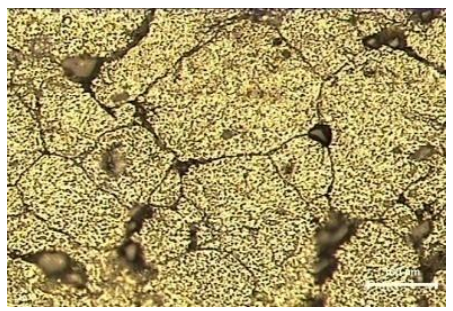

k- $\left(15 \% \mathrm{SiC}, 450 \mathrm{C}^{\circ}\right)$

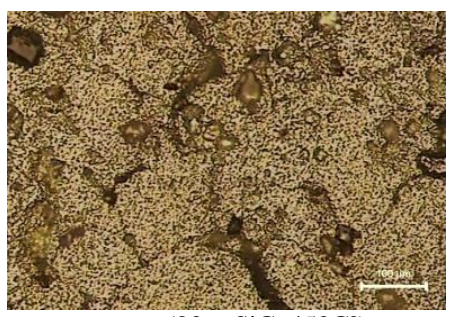

n- $\left(20 \% \mathrm{SiC}, 450 \mathrm{C}^{\circ}\right)$

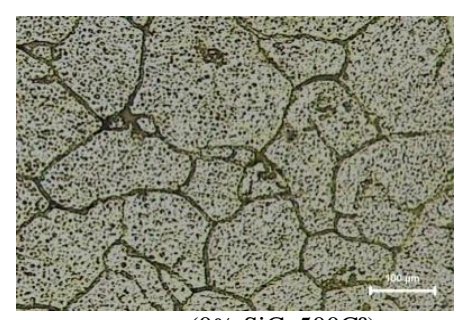

c- $\left(0 \% \mathrm{SiC}, 500 \mathrm{C}^{\mathrm{o}}\right)$

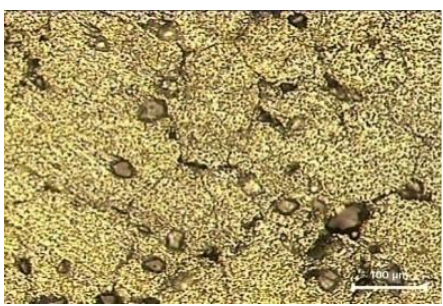

f- $\left(5 \% \mathrm{SiC}, 500 \mathrm{C}^{\circ}\right)$

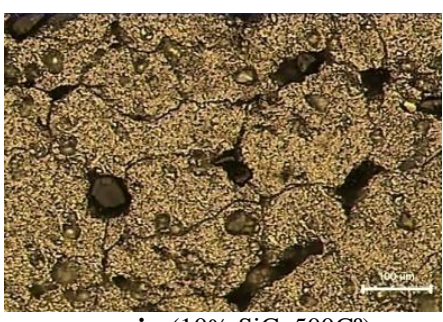

i- $\left(10 \% \mathrm{SiC}, 500 \mathrm{C}^{\circ}\right)$

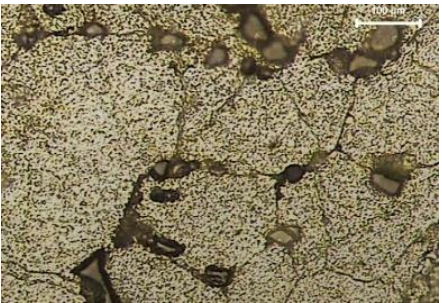

l- $\left(15 \% \mathrm{SiC}, 500 \mathrm{C}^{\circ}\right)$

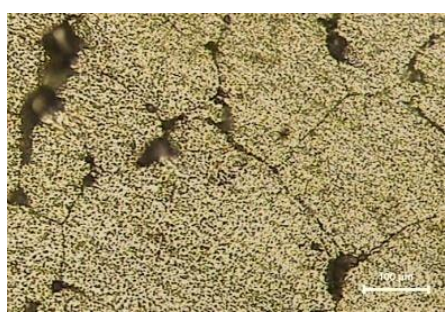

o- $\left(20 \% \mathrm{SiC}, 500 \mathrm{C}^{\circ}\right)$

Fig. 13 OM micrographs at magnification 500x for AA6061-SiC composite hot compacted at $525 \mathrm{MPa}$ for 30 min at (a-c) $0 \% \mathrm{SiC},(\mathrm{d}-\mathrm{f}) \mathbf{5 \%} \mathrm{SiC},(\mathrm{g}-\mathrm{h}) 10 \% \mathrm{SiC},(\mathrm{j}-\mathrm{l}) 15 \% \mathrm{SiC},(\mathrm{m}-\mathrm{o}) 20 \% \mathrm{SiC}$ 
Table2 Average grain size of AA6061-SiC composites after hot compaction.

\begin{tabular}{|c|c|}
\hline Condition & Average Grain Size $(\mu m)$ \\
\hline AA6061, $400^{\circ} \mathrm{C}$ & 18.11 \\
\hline $\mathrm{AA} 6061,450^{\circ} \mathrm{C}$ & 19.11 \\
\hline $\mathrm{AA} 6061,500^{\circ} \mathrm{C}$ & 20.60 \\
\hline $\mathrm{AA} 6061+5 \% \mathrm{SiC}, 400^{\circ} \mathrm{C}$ & 14.22 \\
\hline $\mathrm{AA} 6061+5 \% \mathrm{SiC}, 450^{\circ} \mathrm{C}$ & 14.55 \\
\hline $\mathrm{AA} 6061+5 \% \mathrm{SiC}, 500^{\circ} \mathrm{C}$ & 16.31 \\
\hline $\mathrm{AA} 6061+10 \% \mathrm{SiC}, 400^{\circ} \mathrm{C}$ & 14.08 \\
\hline $\mathrm{AA} 6061+10 \% \mathrm{SiC}, 450^{\circ} \mathrm{C}$ & 14.68 \\
\hline $\mathrm{AA} 6061+10 \% \mathrm{SiC}, 500^{\circ} \mathrm{C}$ & 14.91 \\
\hline $\mathrm{AA} 6061+15 \% \mathrm{SiC}, 400^{\circ} \mathrm{C}$ & 13.74 \\
\hline $\mathrm{AA} 6061+15 \% \mathrm{SiC}, 450^{\circ} \mathrm{C}$ & 14.40 \\
\hline $\mathrm{AA} 6061+15 \% \mathrm{SiC}, 500^{\circ} \mathrm{C}$ & 14.48 \\
\hline $\mathrm{AA} 6061+20 \% \mathrm{SiC}, 400^{\circ} \mathrm{C}$ & 13.21 \\
\hline $\mathrm{AA} 6061+20 \% \mathrm{SiC}, 450^{\circ} \mathrm{C}$ & 13.88 \\
\hline $\mathrm{AA} 6061+20 \% \mathrm{SiC}, 500^{\circ} \mathrm{C}$ & 14.02 \\
\hline
\end{tabular}

Accordingly, these important remarks can be deduced. First, all composite alloy are characterized by a higher hardness compared to the non-reinforced one and it is to the fact that the matrix AA6061 reinforced with $\mathrm{SiC}$ posses higher hardness [24]. Hardness of composite materials increases with increasing content of the reinforcement materials in the metal matrix $(\mathrm{HV} \approx 96$ in the samples that contain $15 \% \mathrm{SiC}$ ) which agreed with [25], but at high volume fraction of $\mathrm{SiC}(20 \%)$, the hardness slightly decreased which, could be attributed to the decreasing compressibility of the composite leading to the increased voids fractions and a decrease in density. At high volume fraction, the insufficiency of the imposed pressure (525 $\mathrm{MPa}$ ) resulted in the segregation of the metal matrix which will be a source of brittleness and resulted in decreasing the density and deterioration of the hardness.

As the volume fraction of $\mathrm{SiC}$ decreases, the diffusion during pressing between the $\mathrm{SiC}$ and aluminium powder reduces. Therefore, in order to increase the incidence of diffusion, the $\mathrm{SiC}$ particle size should be reduced [26]. Consequently, the aluminium powder size must also be reduced to maintain the $\mathrm{SiC}$ particle size to aluminium powder size relationship. Due to the highlighted importance of powder particle size and $\mathrm{SiC}$ volume fraction, it should be noted that as powder particle size decrease and $\mathrm{SiC}$ volume fraction increases the compaction pressure required to achieve higher specific density should increases. Therefore, the selection of a suitable compaction pressure must be based on these parameters for any given composite, so the deterioration of the relative density and of the $\mathrm{HV}$ at relatively higher $\mathrm{SiC}$ volume fraction suggests increasing the $\mathrm{HC}$ pressure up to $650 \mathrm{MPa}$. The selection of aluminium powder size, to be used for any composite, should be based on the $\mathrm{SiC}$ particle size and volume fraction being used for that composite [22]. The average size of the aluminium particles should approximately be the same size, or smaller than that of the $\mathrm{SiC}$ average particle size selected. Also, as the $\mathrm{SiC}$ volume fraction increases the available space between $\mathrm{SiC}$ particles decreases. Therefore, the aluminium average powder size should be decrease with increasing $\mathrm{SiC}$ volume fraction. Second, $\mathrm{SiC}$ works as a grain coarsening obstacle, so the increase of $\mathrm{SiC}$ volume fraction result in grain size refining as shown in table 2, which agree with [27-28], this also leads to increasing the hardness and improving the mechanical properties. Third, it was clear from Figs. 7-12, that, the hot compaction temperature range from $400-500^{\circ} \mathrm{C}$ had insignificant influence on the Vicker's macrohardness for the processed condition and its numerical values were very close. This behaviour could be due to the grains coarsening exhibited with increasing the $\mathrm{HC}$ temperature could have resulted in strain softening, which caused the observed reduction in hardness.

\section{Conclusions}

$\mathrm{SiC}$ particles reinforced AA6061 matrix composites were fabricated using PM technique. Results from the present investigation show that:

1- Hot compaction pressure of $525 \mathrm{MPa}$ is suitable for the densification of the AA6061 powder reinforced with low content of $\mathrm{SiC}$ up to $15 \%$, increasing the $\mathrm{SiC}$ content to $20 \%$ results in increasing the Al-matrices resistance to compressibility and hence, produces lowers densities after HC.

2- Deterioration of $\mathrm{HV}$ values at relatively higher $\mathrm{SiC}$ volume fraction suggests increasing the $\mathrm{HC}$ pressure up to $650 \mathrm{MPa}$.

3- Comparing the relative densities and Vickers hardness values of the hot compacted samples, the $\mathrm{HC}$ temperatures ranging from $400-500{ }^{\circ} \mathrm{C}$ 
had insignificant influence on the densification or on the hardness.

4- Accordingly, the most suitable compaction temperature is $400{ }^{\circ} \mathrm{C}$.

5- The highest hardness values produced corresponding to the AA6061 $+15 \% \mathrm{SiC}$ composite.

6- Increasing $\mathrm{HC}$ temperature up to $500{ }^{\circ} \mathrm{C}$ results in the strain softening due to grain coarsening.

7- Increasing $\mathrm{SiC}$ content retards grain coarsening.

The authors are grateful to Yousef Jamil Science and Technology Research Center (YJSTRC), and the Mechanical Engineering Department, The American University in Cairo-Egypt, for financial support and for their grateful assistance.

\section{References}

[1] Song Min, "Effect of volume fraction of SiC particles on mechanical properties of $\mathrm{SiC} / \mathrm{Al}$ composites", Trans. Nonferrous Met. Soc., Vol.19, pp 1400-1404, 2009. [2] L. Looney, " Production of aluminium matrix composite components using conventional PM technology", Materials Science and Engineering, A303, pp 292-301, 2001.

[3] C. Srinivasa, "2014 and 6061 aluminium alloy-based powder metallurgy composites containing silicon carbide particles/fibres", Material \& Design, Vol. 16, No. 6, 1995. [4] C.S. Shin, " Effect of temper, specimen orientation and test temperature on tensile and fatigue properties of wrought and PM AA6061-alloys", International Journal of Fatigue, Vol. 26, pp 691-703,2004.

[5] G.G. Doncel," Additively of reinforcing mechanisms during creep of metal matrix composites: Role of the microstructure and the processing route", Journal of Alloy and Compounds, Vol.475, pp 202-206, 2009.

[6] N. Ashgriz, "Preparation of aluminium/silicon carbide metal matrix composites using centrifugal atomization",

Powder Technology, Vol. 184, pp 11-20, 2008.

[7] J. B. Fogagnolo, "Mechanically alloyed AIN particlereinforced Al-6061 matrix composites: Powder processing, consolidation, mechanical strength and hardness of the as-extruded materials", Materials Science and Engineering, A426, pp 85-94, 2006.

[8] J. B. Fogagnolo, "Mechanically milled AA6061/ $\left(\mathrm{Ti}_{3} \mathrm{Al}\right)_{\mathrm{p}} \mathrm{MMC}$ reinforced with intermetallics - the structure and properties", Journal of Materials Processing Technology, Vol. 155, 2004.

[9] M. E. Smagorinski, "The properties and microstructure of Al-based composites reinforced with ceramic particles", Materials Science and Engineering, A244, pp 86-90, 1998. [10] N. Showaiter, "Compaction, sintering and mechanical properties of elemental $6061 \mathrm{Al}$ powder with and without sintering aids", Material and Design, Vol. 29, pp 752-762, 2008.

[11] W. J. Kim, "Superplasticity in PM $6061 \mathrm{Al}$ alloy and elimination of strengthening effect by reinforcement in super plastic PM aluminum composites", Materials Science and Engineering, A298, pp 166-173, 2001. [12] P. Iglesias, "A study of the wear behaviour of polymer-matrix composites containing discontinuous nanocrystalline alloy reinforcements", Tribology International, Vol. 40, pp 479-489, 2007.

[13] J. B. Fogagnolo, "6061 Al reinforced with silicon nitride particles processed by mechanical milling", Scripta Materialia, Vol. 47, pp 243-248, 2002.

[14] S.A. Meguid, "On the tensile and shear strength of nano-reinforced composite interfaces", Material and Design, Vol. 25, pp 289-296, 2004.

[15] J.L. Ortiz, "Microstructure and mechanical behaviour of $6061 \mathrm{Al}$ reinforced with silicon nitride particles, processed by powder metallurgy", Scripta Materialia, Vol. 42, pp 383-388, 2000.

[16] C. Yan, "Multi-functional SiC/Al composities for aerospace applications", Chinese Journal of Aerospace, Vol. 21, pp 578-584, 2008.

[17] M.R. Rosenberger, "Wear of different aluminium matrix composites under conditions that generate a mechanically mixed layer", Wear, Vol. 259, pp 590-601, 2005.

[18] J.H. Lee, "Characteristics of ceramic particle reinforced $\mathrm{Al}$ composite powder manufactured by a stone mill type crusher using twin roll cast Al alloy flake: a model on the formation of composite powder", Materials Science and Engineering, A304, pp 632-636, 2001.

[19] D. Huda, "Molding for the compressive strength of A1-6061/SiC MMCs", Journal of Materials Processing Technology, Vol. 56, pp 452-462, 1996.

[20] [136] E. Cerri, and E. Evangelsta, " Metallography of aluminum alloys", European Aluminum Association, 1999.

[21] T.W. Kim, "Determination of densification behaviour of Al-SiC metal matrix composites during consolidation processes", Materials Science and Engineering, A483, pp 648-651, 2008.

[22] T.W. Kim, "Densification behaviour of aluminium alloy powder under cold compaction", International Journal of Mechanical Science, Vol. 44, pp 1295-1308, 2002.

[23] Cheng Xu," Three dimensional representations of hardness distributions after processing by HPT", Materials Science and Engineering, A503, PP 71-74, 2008.

[24] G.B. Veeresh Kumar, " Studies on Al6061-SiC and Al 7075- $\mathrm{Al}_{2} \mathrm{O}_{3}$ Metal Matrix Composites", Journal of Minerals \&Materials Characterization \& Engineering, Vol. 9, No. 1, pp. 43-55, 2010.

[25] C. E. da Costa, "Properties of AA6061 Aluminium Alloy Reinforced with Different Intermetalics and Ceramics Particles", Materials Science Forum, vol. 530531, pp255-260, 2006.

[26] G. Wu, "Microstructure and mechanical properties of $\mathrm{SiC}_{\mathrm{W}} \& \mathrm{AL}_{2} \mathrm{O}_{3} / 6061$ composites", Scripta Materialia, Vol. 28, pp 683-688, 1993.

[27] Z. Peng, "Effect of particle characteristics on deformation of particle reinforced MMC", Trans. Nonferrous Met. Soc. China, Vol. 20, pp 655-661, 2010. 
[28] N. Zhao, "The effect of mechanical alloying on SiC distribution and the properties of 6061 aluminium composite", Journal of Materials Processing Technology, Vol. 170, pp 586-592, 2005. 